\title{
Crashworthiness Analysis of the Placentia, CA Rail Collision
}

\author{
D Parent*, D Tyrell*, and A B Perlman** \\ *Volpe National Transportation Systems Center, Cambridge MA, US \\ **Mechanical Engineering, School of Engineering, Tufts University, Medford MA, US
}

\begin{abstract}
The Volpe Center is supporting the Federal Railroad Administration in performing rail passenger equipment crashworthiness research. The overall objective of this research is to develop strategies for improving structural crashworthiness and occupant protection. A field study of passenger train accidents is being conducted to investigate the causal mechanisms of how train occupants are injured during accidents. The investigation of the April 23, 2002 collision in Placentia, CA has motivated the development of occupant protection strategies. This process began with two simulation models: a collision dynamics model and an occupant response model. These simulations suggested that impact with workstation tables brought about fatal thoracic and abdominal injuries in two occupants. Workstation tables that limit and distribute the abdominal loads are currently under investigation through modeling and full-scale testing with advanced anthropomorphic test devices.
\end{abstract}

\section{INTRODUCTION}

The Volpe Center has been supporting the Federal Railroad Administration in performing rail passenger equipment crashworthiness research. The overall objective of this research has been to develop strategies for incrementally improving structural crashworthiness and occupant protection. The structural crashworthiness research involves the modification of passenger rail equipment to preserve the occupant volume [1]. Preservation of the occupant volume is a necessity for preventing life-threatening injuries in rail collisions. Once the occupant volume is preserved, occupant protection strategies can be implemented to reduce injury risk.

The objective of the occupant protection research is to evaluate occupant response in rail collisions, identify interior configurations for improvement of occupant safety, and develop improved occupant protection strategies for those configurations. There are three aspects to this research. First, accident investigations are conducted to identify the most common rail collision scenarios, along with the related modes and severities of the injuries to the occupants. Second, dynamic sled testing and full-scale testing are carried out to measure the occupant response and evaluate occupant protection strategies. Third, computer modeling is used to supplement sled and full-scale testing as well as determining the likely occupant response in common rail collision scenarios.

This approach ensures the most efficient use of data from rail collisions, so that similar injuries can be prevented in the future. This paper describes how information collected from the Placentia, CA rail collision has been used in the development of improved occupant protection strategies. This collision was unique in that the mode of failure of the impacted passenger car was uncharacteristic, and there were two occupants who sustained fatal injuries from impacts with workstation tables. Thus, the workstation tables have been identified as an injury hazard, and the process of developing and testing countermeasures has begun.

\section{APPROACH}

The development of occupant protection strategies is a continual effort aimed at preventing the serious and fatal injuries sustained in rail collisions and derailments. Since these incidents are relatively rare, statistics alone are not sufficient to identify and develop countermeasures for the areas of concern. Full-scale testing and computer simulation supplement the information collected during accident investigations. The general approach to occupant protection studies is summarized in Figure 1. 


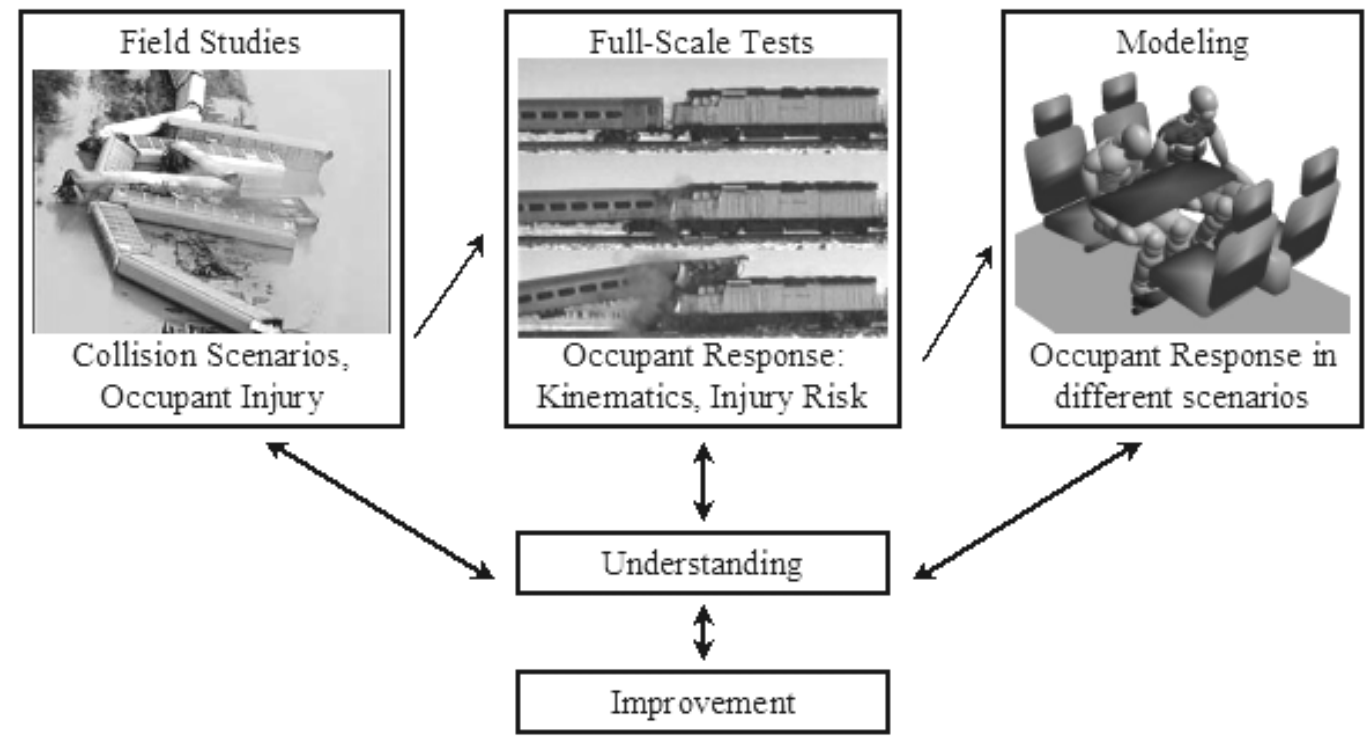

Figure 1 - Approach to occupant protections studies

A field study of passenger train accidents is currently being conducted. In the event of a collision, investigators seek to characterize the occupant environment. The occupant environment includes the deceleration of the occupant volume and the characteristics of the interior structures. An understanding of the occupant environment facilitates the determination of causal mechanisms for the injuries to the train occupants. The scenarios where improved occupant protection strategies are most likely to prevent serious or fatal injuries are identified for further study.

Full-scale testing of passenger rail equipment is carried out for the most likely scenarios identified by the literature review and field studies. Included in the full-scale tests are Anthropomorphic Test Devices (ATDs, or test dummies) to measure the occupant response. Key components of the measured response are occupant kinematics and injury risk. Dynamic sled testing can also be used to evaluate the occupant response in rail collisions, as well as analyzing occupant protection strategies.

Computer modeling supplements both full-scale testing and crash investigations. Multi-body dynamics occupant response computer models are developed and refined based on the results from fullscale testing. These models estimate the occupant kinematics and injury risk, as well as verifying compartmentalization. Models are useful because they are much less expensive and time-consuming than full-scale testing, thus can be used to analyze a wide range of occupant environments. Furthermore, computer models can be used to supplement the accident investigations in order to clarify any uncertainties.

\section{Placentia, CA Approach}

The mode of structural failure of the impacted passenger car the Placentia, CA collision resulted in high longitudinal acceleration and significant lateral motion. This environment was aggravated by the inability of the interior structures to compartmentalize the occupants. Occupants seated at workstation tables sustained the most severe injuries associated with the collision.

The first step in the analysis of the Placentia, CA collision was an investigation of the scene. To clarify the details of the occupant environment, two models were created. First, a collision dynamics model was used to estimate the gross motions of the cars in the passenger train. The deceleration of the occupants relative to the impacted car was approximated by the occupant response model. Both the accident investigation and the models identified thoracic and abdominal injuries from impact with 
workstation tables and subsequent loss of compartmentalization as the likely cause of the fatal injuries sustained by two occupants.

The next step in the analysis of the Placentia, CA collision was to conduct a full-scale test in a similar occupant environment. Experimental ATDs with an increased capacity for measuring thoracic and abdominal injury were used on this test. The final step in the process will be to construct and test an improved crashworthiness design workstation table.

\section{ACCIDENT INVESTIGATION}

On April $23^{\text {rd }}, 2002$, an eastbound freight train approached a westbound passenger train on the same track. The conductor of the passenger train was able to see the freight train, and brought the passenger train to a complete stop at the Atwood control point in Placentia, California. At approximately 8:10 a.m., the freight train, though in full emergency braking at the time, collided with the passenger train. The passenger train had been traveling in a cab car leading arrangement, where the cab car was the westernmost car in the passenger train $[2,3]$. Thus, the lead locomotive in the freight train collided with the cab car in the passenger train. Figure 2 shows the arrangement of each train.

In a typical head-on collision, the impacted end of the car is expected to crush longitudinally, parallel to the tracks. However, in this case, the majority of the crush occurred towards the rear of the lead car in the passenger train and perpendicular to the tracks, as shown in Figure 3. The lateral accelerations generated by this form of structural collapse aggravated the loss of compartmentalization of the occupants. These accelerations, combined with already severe longitudinal accelerations, made for a notably harsh occupant environment.

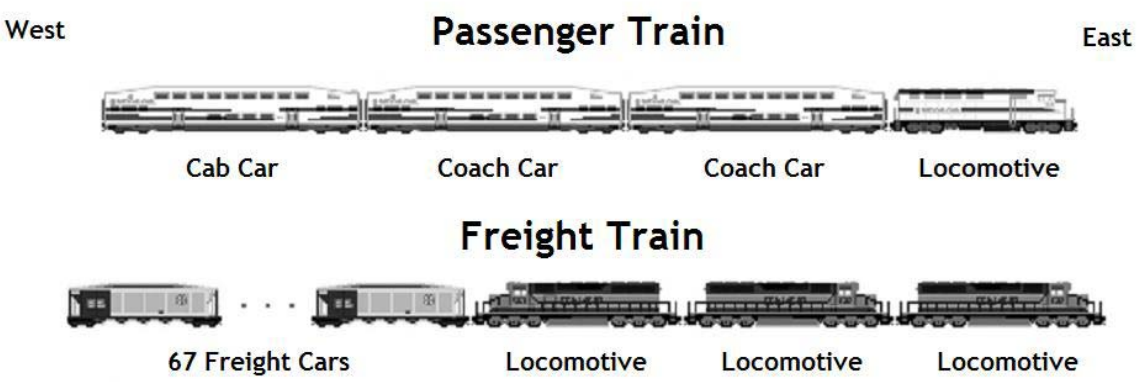

Figure 2 - Arrangement of the passenger and freight trains involved in the Placentia, California rail collision. The direction of travel of the freight train was east, as the lead locomotive in the freight train struck the cab car in the passenger train.

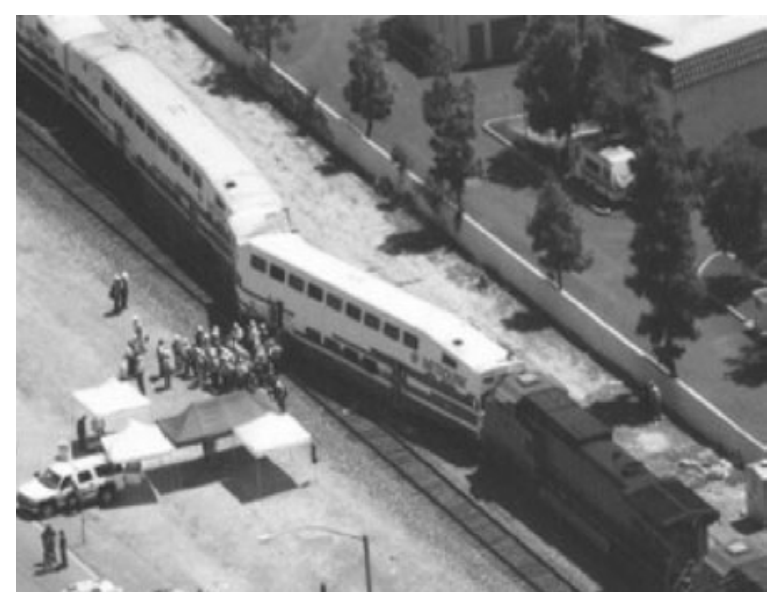

Figure 3 - Damage to MetroLink cab car after collision with locomotive-led freight train [3]. 
Overall, 161 of the passengers and crew were transported to local hospitals. Two of these passengers sustained fatal injuries [2,3]. Both of the passengers who sustained fatal injuries were seated in facingseat configuration with an intervening workstation table. Along with these two fatalities, there were several other serious injuries sustained by passengers seated adjacent to the workstation tables. The injuries consisted of broken ribs, lacerations of organs in the abdominal cavity, and a wide variety of facial injuries [4].

\section{MODELING}

In order to use the accident investigation data to develop strategies to protect the occupants in this and similar scenarios, additional analysis of the occupant response is necessary. The information obtained from the accident investigation was useful in characterizing several aspects of the occupant environment, such as the interior structures impacted by the occupants and the modes and severities of injury. However, there were several aspects of the investigation that were inconclusive. Models were used to simulate the Placentia collision and corroborate the investigation data. First, a collision dynamics model approximated the acceleration pulse brought about by the structural failure of the impacted cab car. This model also supported evidence of the impact velocity, which is necessary to determine the acceleration pulse. This acceleration pulse was the input into an occupant response model, which estimated the kinematics and injury risk to the occupants.

\section{Collision Dynamics Model}

The collision dynamics model used to simulate this collision was created using MSC.ADAMS version 12.0 software [5]. This model was based on a one-dimensional model used to simulate the fullscale train-to-train impact test [6]. This model simulates the impact of a moving locomotive-led freight train with a stationary cab car-led passenger train. Each passenger car is represented by a lumped mass and attached to subsequent passenger cars with non-linear springs that simulate the dynamic structural behavior of the car end. The force-crush characteristic of these non-linear springs has been determined from previous modeling and full-scale testing of passenger cars [6]. To account for the mode of deformation experienced during the collision, the cab car was divided into two rigid bodies attached with an additional non-linear spring. The characteristic of this non-linear spring was varied iteratively to achieve the proper deformation. The two force-crush characteristics used in the collision dynamics model are shown in Figure 4.

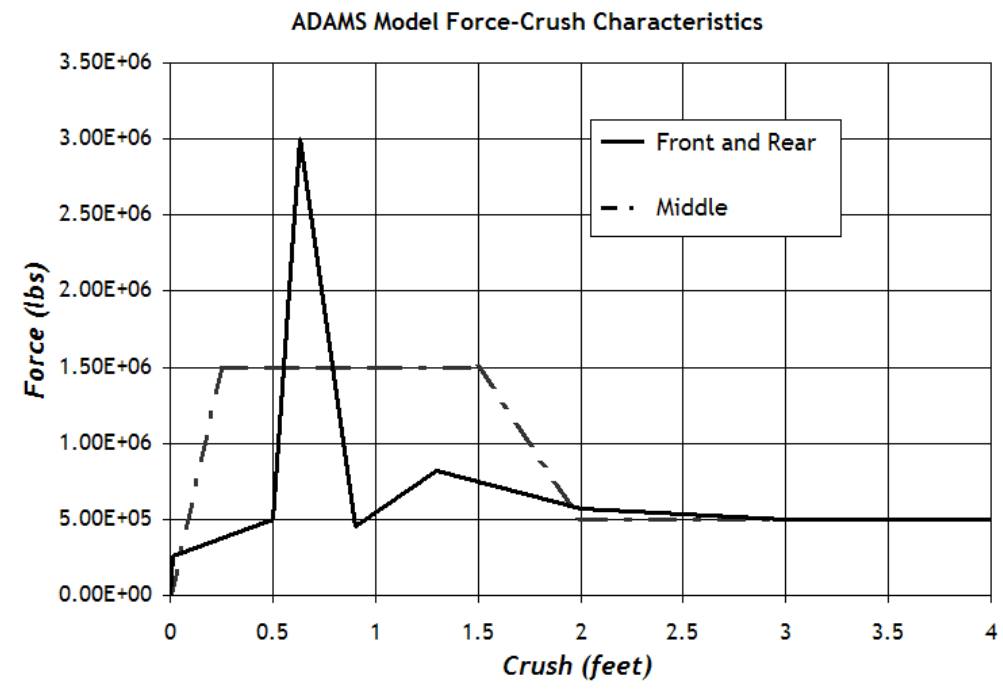

Figure 4 - Force-crush used in the ADAMS model of the Placentia, CA collision. 
To determine the acceleration-time history of the passenger train, the impact velocity is necessary. One way to determine the impact velocity is to determine the distance traveled by the freight train after the impact. Since the freight train was nearly a mile long, the addition of the passenger train to the consist after impact should not have significantly affected the stopping distance. The collision dynamics model predicts the combined consist traveling 235 feet after the impact.

Additional evidence was provided by the investigators to estimate this distance. One was the video from a surveillance camera from a nearby factory. While this camera did not capture the actual impact, the investigators were able determine the location of the impact. Based on this evidence, the distance traveled after impact was estimated to be 243 feet $[2,3]$. Another source of evidence to provide clarification was the event recorder of the lead locomotive in the freight train. These data are sparse, recording the velocity of the train in one mile per hour increments at a sampling rate of one data point per second. This data alone is not sufficient to determine the deceleration-time history of the impacted passenger car, since the duration of the impact is on the order of 250 milliseconds. However, it does allow a correlation to be drawn relating the impact velocity to the distance traveled by the combined consist after the collision. A velocity-distance graph is shown in Figure 5. This graph shows the distance traveled by the combined consist on the $\mathrm{x}$-axis and the corresponding velocity on the $\mathrm{y}$-axis. The data from the event recorder is shown as black diamonds, and the collision dynamics model is shown as a gray line.

The collision dynamics model was iteratively improved by varying the impact velocity, force-crush characteristics, and friction and damping coefficients until the results corresponded with the data from the accident investigation [7]. The most important output from the collision dynamics model is the acceleration pulse seen in the front section of the impacted passenger car, where the occupants who sustained fatal injuries were seated. The correlation of the collision dynamics model with the collision investigation information, most importantly the event recorder data, provides confidence that this acceleration pulse is representative. This acceleration pulse is used as the input for the occupant response model. The acceleration in the longitudinal direction at the center of gravity of the cab car is shown in Figure 6.

Black Box Data vs. ADAMS Model

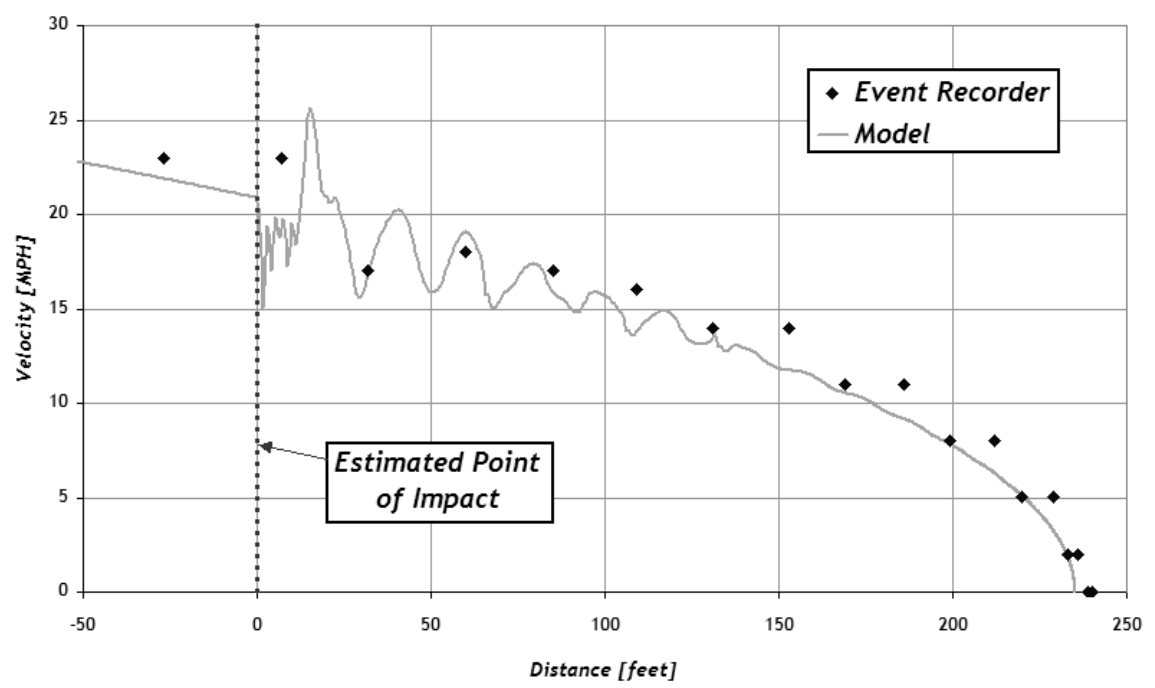

Figure 5 - Velocity vs. distance comparison of the lead freight locomotive event recorder with the most characteristic case. 


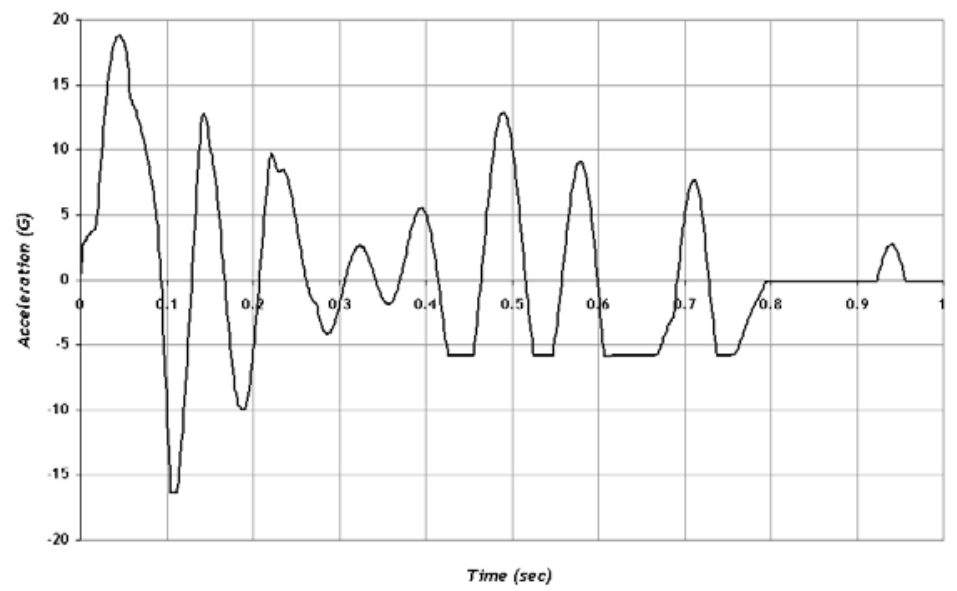

Figure 6 - Acceleration output seen at the center of gravity of the cab car from the ADAMS model [7].

\section{Occupant Response Model}

When evaluating the occupant response in a rail collision, occupant kinematics and injury risk are considered. Occupant kinematics, the motion of the occupant during a collision, includes the biomechanical response of the body to impacts with the interior structures. The velocity, position, and orientation of the occupant affects the mode and severity of injuries brought about from secondary impacts. An important aspect of the occupant kinematics is the ability of the interior structures of the rail car to limit the motion of an occupant during a collision, often referred to as compartmentalization. Compartmentalization is lost, for instance, if an occupant overrides a forward seat back or travels laterally into the aisle of the passenger car. Generally speaking, the velocity of an occupant relative to the passenger car will increase until an interior structure is impacted. Thus, as the distance traveled by the occupant increases, the secondary impact velocity increases as well, which, in turn increases the risk of injury to the occupant. Compartmentalization has been shown to be an effective occupant protection strategy [8].

In full-scale testing and computer modeling, measurements of loads and accelerations are taken to evaluate the risk of injury to the head, chest, neck, and femurs of the occupant. These measurements are compared to maximum injury criteria values to determine the injury risk to the occupant. Injury criteria that have commonly been used in these studies are the head injury criterion (HIC), neck injury criterion (Nij), chest deceleration ( $3 \mathrm{~ms})$, and femur load.

The occupant response model is a multi-body dynamics model implemented in MADYMO 6.0 [9]. The objective of this model is to simulate the most likely occupant response based on the available evidence. The model is used to evaluate the kinematics and injury risk of the occupant. These factors correspond to the evidence collected from the accident investigation. From the accident investigation, it appears that both of the occupants who sustained fatal injuries were not compartmentalized. The longitudinal acceleration pulse estimated by the collision dynamics model was applied to the occupant response model. To account for the lateral motion of the cab car during the collision, the longitudinal acceleration pulse was scaled down and applied to the occupant response model in the lateral direction.

From the accident investigation, it was suggested that blunt abdominal trauma contributed to the injuries that resulted in the two fatalities. Evaluating the injury risk due to blunt abdominal trauma is difficult because there are currently no widely accepted abdominal injury criteria. In the United Kingdom, where seating arrangements with workstation tables are common, suggested tolerances have been proposed for two important measures of abdominal injury [10]. The first is that the overall force that can be sustained should be below $6.73 \mathrm{kN}$. The second is the visco-elastic response of the abdomen, 


\begin{tabular}{|c|l|c|l|c|c|}
\hline Location & \multicolumn{1}{|c|}{ Criterion } & Maximum & \multicolumn{1}{|c|}{ Units } & Occupant A & Occupant B \\
\hline \multirow{4}{*}{ Thorax } & Chest Deflection & 63 & $\mathrm{~mm}$ & 63.9 & 61.9 \\
\cline { 2 - 6 } & Chest Acceleration & 60 & $\mathrm{G}$ & 49.4 & 45.2 \\
\cline { 2 - 6 } & Viscous Criterion & 1.0 & $\mathrm{~m} / \mathrm{s}$ & $\mathbf{1 . 6 3}$ & $\mathbf{1 . 2 6}$ \\
\cline { 2 - 6 } & CTI & 1.0 & & $\mathbf{1 . 2 0}$ & $\mathbf{1 . 5 3}$ \\
\hline \multirow{2}{*}{ Abdomen } & Peak Force & 6.73 & $\mathrm{kN}$ & 1.90 & $\mathbf{6 . 9 0}$ \\
\cline { 2 - 6 } & Viscous Criterion & 1.98 & $\mathrm{~m} / \mathrm{s}$ & 0.58 & 0.96 \\
\hline
\end{tabular}

Table 1 - Injury measurements from the occupant simulation in Placentia, CA collision [7].

similar to that of the chest, also labeled the viscous criterion. For the abdomen, the viscous criterion should be below $1.98 \mathrm{~m} / \mathrm{s}$.

The occupant response model used to assess injury criteria includes the two occupants that sustained fatal injuries. Recreating the occupant kinematics is difficult, since it is impossible to discern the exact motions and initial positions of the injured occupants; however, the investigation identified several interior structures that were likely to have been impacted. Many possible initial positions were simulated and compared with the accident investigation data. The results from the most characteristic case are shown in Table 1. In the model, both occupants experienced chest deflection and chest acceleration values very close to the tolerance level, and the thoracic viscous criterion and combined thoracic index both exceed the tolerance level [7]. Therefore, these models indicate that there is a high probability of the occupant sustaining a serious injury, confirming the assessment that workstation tables contributed to the fatal injuries sustained by two of the occupants in the Placentia, CA collision.

The simulations suggest that the workstation table should have two important characteristics to protect the occupant. First, the table should compartmentalize the occupant. If the table gives way, the occupant will impact additional interior structures at a higher velocity. Compartmentalization can be accomplished by strengthening the table attachments and frame. Second, the table should have an edge that both limits and distributes the load imparted on the abdomen. The force-crush characteristic of the edge of the table must be optimized to achieve this objective. To design an improved crashworthiness workstation table, both of these factors must be implemented to minimize the injury risk to the occupant.

\section{FULL-SCALE TESTING}

To establish criteria for an improved workstation table design, the crashworthiness performance of the current tables was included on a full-scale impact test of two rail passenger vehicles into a fixed barrier. This test was one in a series being conducted to measure the crashworthiness performance of conventional rail passenger equipment and demonstrate the effectiveness of improved-crashworthiness equipment. Prior tests in this series have included interior experiments to measure the occupant response using ATDs. Five occupant experiments were included on this test, conducted on February 26, 2004. Two of these experiments tested a seating arrangement similar to the facing seats with workstation table arrangement on the cab car in the Placentia, CA collision. Information for modeling purposes and for determining table design criteria was measured in these experiments.

The Test Device for Human Occupant Restraint (THOR) was used to characterize abdominal and thoracic injury. Standard Hybrid III ATDs have a limited capacity of taking lower thoracic and abdominal measurements. In addition, an ATD referred to as the Hybrid 3RS test dummy, developed for the United Kingdom's Rail Safety and Standards Board, was used to make comparable measurements. The Hybrid 3RS incorporates many of the thoracic and abdominal advancements of the THOR ATD into a Hybrid III ATD.

The workstation tables used in this test were modified versions of the type involved in the Placentia collision. The table attachments were strengthened to ensure compartmentalization of the occupant. This modification guarantees measurement of the maximum loads imparted on the table by the occupant. The maximum loads will be used to define the required strength of the attachments of an improved 
crashworthiness design. The table loads also provide an estimate of the peak abdominal load experienced by the occupant.

The MADYMO occupant response model that was used in the Placentia, CA simulations was modified to simulate occupant environment for the full-scale two-car impact test. This model was the basis for positioning the ATDs and selecting the appropriate instrumentation channels. An acceleration pulse obtained from a three-dimensional collision dynamics model of the impact test [11] was used as the input to the occupant simulation. The longitudinal component of the acceleration pulse is expected to be similar in severity to that of the Placentia, CA collision. Figure 7 shows the estimated occupant response in the full-scale two-car test. The model results indicate that the impact of the table on the abdomen of the ATD would exceed the proposed injury criteria values. The peak load and viscous criterion were predicted to be greater than the suggested tolerances of $6.73 \mathrm{kN}$ and $1.98 \mathrm{~m} / \mathrm{s}$ respectively [12].

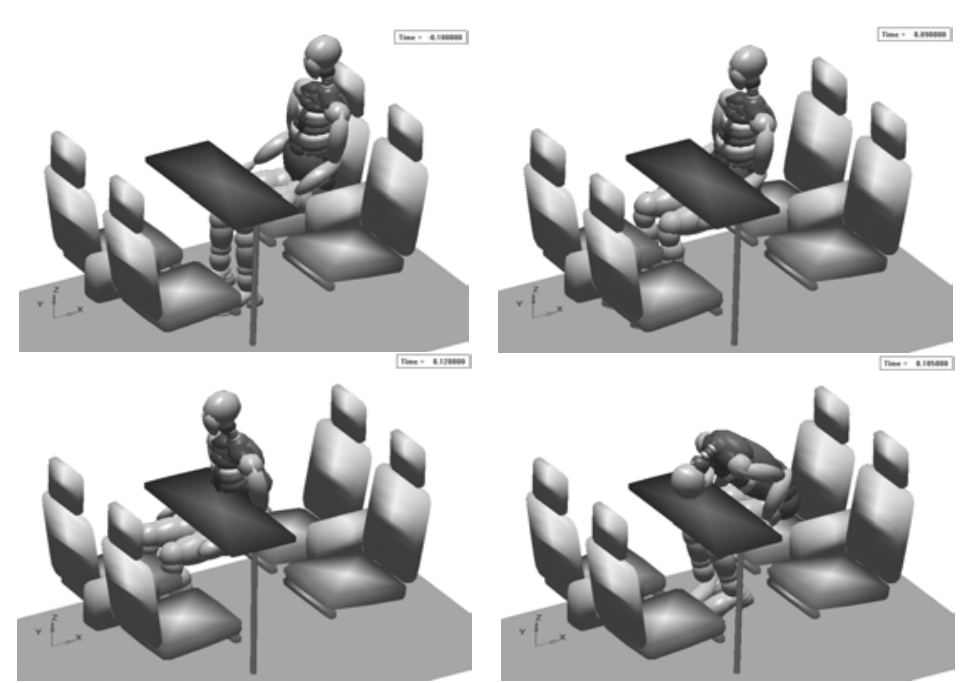

Figure 7 - Occupant response model for THOR in two-car full-scale test. Images show initial position (top left), initial impact with table (top right), maximum compression of abdomen (bottom left), and head impact with tabletop (bottom right).

The preliminary data from the full-scale two-car impact test is in agreement with the model results. Since the workstation table attachments did not fail, the occupant was successfully compartmentalized. Both the kinematics and the measured thoracic and abdominal displacement-time histories show agreement with the pre-test model [12]. As expected, the proposed abdominal force and abdominal viscous criterion injury criteria values were exceeded. The images below show the pre-test and post-test positions of the Hybrid 3RS (Figure 8) and THOR (Figure 9) test devices.

Figure 8 - Hybrid 3RS ATD before (left) and after (right) two-car full-scale test

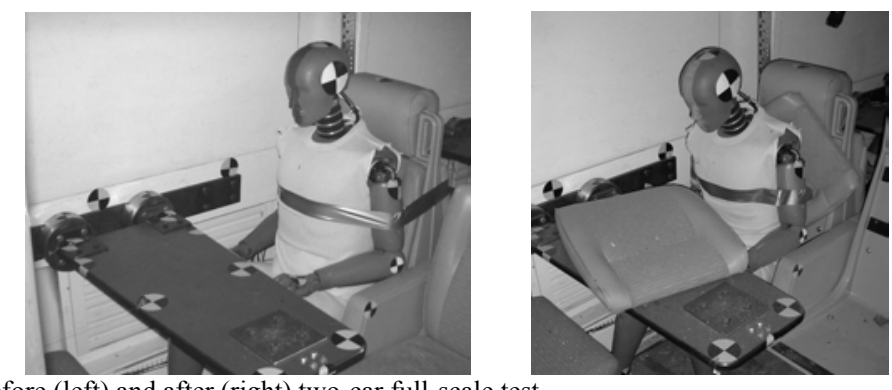




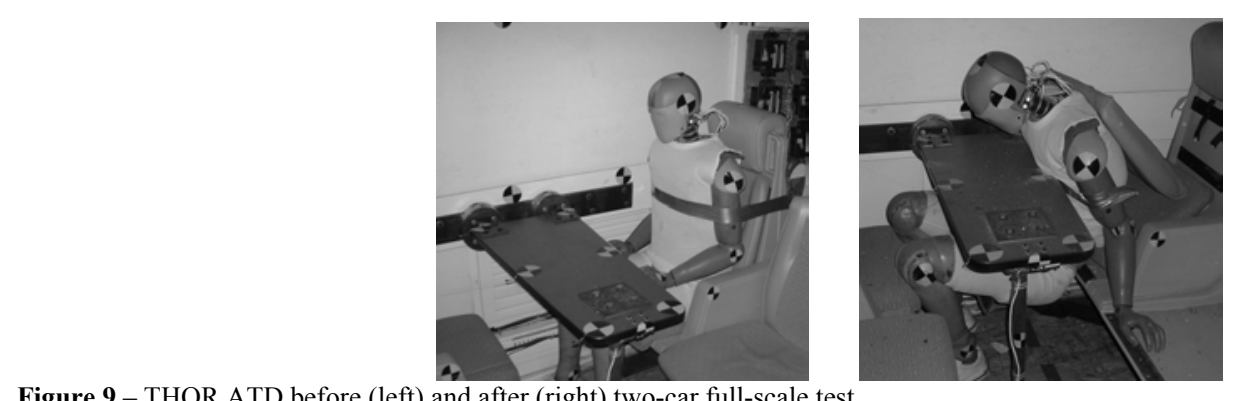

Figure 9 - THOR ATD before (left) and after (right) two-car full-scale test

\section{DISCUSSION AND CONCLUSION}

The data collected from the occupant experiments on the full-scale two-car impact test will be used for several purposes. The peak table attachment loads measured during the test will be used to form the strength criteria for an improved crashworthiness design. Along with the table loads, the thoracic and abdominal displacements and accelerations will be used to refine the occupant response model. The ability of the experimental test dummies to estimate abdominal injury will be investigated. The kinematics and injury measurements for the Hybrid 3RS and THOR ATDs will be compared. This work is part of a collaborative effort with the UK's Rail Safety and Standards Board to determine the reliability of these test dummies.

The occupant protection strategy to mitigate the injury risk associated with workstation tables requires both strengthening the table attachments and integrating a frangible table edge to limit and distribute the abdominal load. Several steps are necessary to implement this strategy. First, the refined occupant response model will be used to develop design criteria. An idealized force-crush characteristic of the table edge will be developed from simulations using this model. Second, these criteria will be used to evaluate potential table designs. Finally, one or more candidate designs will be constructed and assessed in a combination of dynamic sled testing and experiments on the full-scale crash energy management train-to-train impact test scheduled for 2005.

This paper describes the process of developing occupant protection strategies carried out after the Placentia, California rail collision on April 23, 2002. This process began with an in-depth investigation of the accident. Next, a collision dynamics model was created that clarifies some aspects of the investigation and established unknown elements of the occupant environment. An occupant response model, based on relevant characteristics of the occupant environment, confirmed that impact with the workstation tables brought about serious and fatal thoracic and abdominal injuries to the passengers. This conclusion focused attention on the improvement of design of the workstation tables. Experiments on a full-scale impact test using the Hybrid 3RS and the THOR, estimated thoracic and abdominal injury from impact with the tables. The next step in the process, currently underway, is to identify countermeasures to reduce the risk of thoracic and abdominal injury from workstation tables. The improved crashworthiness design is expected to successfully protect occupants seated at workstation tables.

\section{ACKNOWLEDGMENTS}

The research discussed in this paper was performed as part of the Equipment Safety Research Program sponsored by the Office of Research and Development of the Federal Railroad Administration. The authors would like to thank Dr. Tom Tsai, Program Manager, and Ms. Claire Orth, Division Chief, Equipment and Operating Practices Research Division, Office of Research and Development, Federal Railroad Administration, for their support.

This scope of this paper ranges from accident investigation, to simulation modeling, to fullscale testing. The author's would like to thanks Michael Flanigon, Investigator in Charge, Richard Downs, Survival Factors Group Leader, and Frank Ciacci, Forensic Investigator, National Transportation Safety Board for their assistance in the 
investigating the Placentia, California train collision, and to thank Grady Cothen, Acting Associate Administrator for Safety Enforcement and Jo Strang, Deputy Associate Administrator for Railroad Development for their efforts to coordinate the accident investigations with the National Transportation Safety Board. The authors would also like to thank Gunars Spons, Federal Railroad Administration Resident Manager at the Transportation Technology Center, for managing the full-scale test effort, and Mark Haffner, THOR Program Manager, National Highway Transportation Safety Administration, for the use of the THOR ATD.

Ongoing work on occupant protection in rail passenger equipment is being conducted cooperatively with the United Kingdom's Rail Safety and Standards Board. This work is being coordinated with Alan Lawton, Head of Technical Services, Rail Safety and Standards Board. Peter Matthews, Project Leader, AEA Technologies, plc, leads the UK's research on rail equipment occupant protection.

\section{REFERENCES}

[1] Tyrell, D.C., Severson, K.J., Marquis, B.J., "Crashworthiness of Passenger Trains", US Department of Transportation, Federal Railroad Administration, DOT/FRA/ORD-97/10, 1998.

[2] National Transportation Safety Board, "Head-On Collision Between BNSF and Metrolink Trains, and Subsequent Derailment, in Placentia, California on April 23, 2002: Factual Report, Survival Factors Issues." DCA02-MR-004, 2/20/03.

[3] National Transportation Safety Board. 2003. Collision of Burlington Northern Santa Fe Freight Train with Metrolink Passenger Train Placentia, California, April 23, 2002. Railroad Accident Report NTSB/RAR-03/04. Washington, DC.

[4] “Placentia, California Occupant Investigation,” Dynamic Sciences, Inc, 2003, pp. 15-16.

[5] MSC.ADAMS, Version 12.0, MSC.Software Corporation, Ann Arbor, Michigan.

[6] Tyrell, D., and Perlman, A. B., 2003, "Evaluation of Rail Passenger Equipment Crashworthiness Strategies," Transportation Research Record, Rail, Paper no. 03-4530.

[7] Parent, D., "The Forensic Crashworthiness Analysis of the Placentia, CA Rail Collision," Undergraduate Honors Thesis, Tufts University, May 2003.

[8] Tyrell, D.C., Severson, K.J., Marquis, B.J., "Analysis of Occupant Protection Strategies in Train Collisions," ASME International Mechanical Engineering Congress and Exposition, AMD-Vol. 210, BED-Vol. 30, pp. 539-557, 1995 .

[9] MADYMO, Version 5.4.1/6.0/6.1, TNO Automotive, Delft, The Netherlands.

[10] Wallace, W. Angus and Srinivasan, Sreebla C. M. "Rail Passenger \& Crew Survivability Studies - Part 2." November 2002.

[11] Jacobsen, K., Tyrell, D., Martinez, E. "Impact Tests of Crash Energy Management Passenger Rail Cars: Analysis and Structural Measurements", to be presented at the November, 2004 ASME Congress and Exposition.

[12] Severson, K., Parent, D., Tyrell, D., "Two-Car CEM Test Results - Volume 2, Occupant Experiments" to be presented at the November, 2004 ASME Congress and Exposition. 